\title{
Molten salt synthesis of spinel-type $\mathrm{LiTi}_{2} \mathrm{O}_{4}$
}

\author{
Nobuhiro KUMADA, ${ }^{\dagger}$ Mirza Humaun Kabir RUBEL, Akira MIURA and Takahiro TAKEI
}

Center for Crystal Science and Technology, University of Yamanashi, 7-32 Miyamae, Kofu 400-8511, Japan

\begin{abstract}
Spinel-type $\mathrm{LiTi}_{2} \mathrm{O}_{4}$ was prepared directly by the reaction of lepidocrocite-type potassium titanate and molten $\mathrm{LiCl}$ at $750-850^{\circ} \mathrm{C}$ in a stream of $\mathrm{H}_{2}$ gas. The $\mathrm{Li} / \mathrm{Ti}$ ratio in the spinel-type phase prepared at $850^{\circ} \mathrm{C}$ was 0.54 , and the lattice parameter and superconductive critical temperature $T_{c}$ were $a=8.3935(2) \AA$ and $12.3 \mathrm{~K}$, respectively. The product at $750^{\circ} \mathrm{C}$ exhibited no superconductive diamagnetism down to $2.5 \mathrm{~K}$, and the product at $800^{\circ} \mathrm{C}$ showed weak superconductive diamagnetism at $10.5 \mathrm{~K}$. The morphology of the particles prepared at $850^{\circ} \mathrm{C}$ showed an irregular shape with a particle size of $1-10 \mu \mathrm{m}$.
\end{abstract}

(2014 The Ceramic Society of Japan. All rights reserved.

Key-words : Spinel-type $\mathrm{LiTi}_{2} \mathrm{O}_{4}$, Molten salt synthesis, Superconductivity

[Received December 2, 2013; Accepted February 11, 2014]

\section{Introduction}

Lithium titanate $\mathrm{LiTi}_{2} \mathrm{O}_{4}$ with a spinel-type structure is a superconductor with $T_{c}=13 \mathrm{~K}$ which was discovered by Johnston et al. in 1973. ${ }^{1)}$ This spinel-type lithium titanate has a wide composition range, $\mathrm{Li}_{1+x} \mathrm{Ti}_{2-x} \mathrm{O}_{4}(0 \leq x \leq 1 / 3)$, and $T_{c}$ depends on the chemical composition. ${ }^{2)}$ It was difficult to reproducibly prepare a powder sample of $\mathrm{LiTi}_{2} \mathrm{O}_{4}$ with identical superconducting properties because of the volatility of lithium and the phase change at high temperature. ${ }^{2)}$ Various synthesis methods have been proposed. Johnston et al. attempted the preparation of the Li-Ti-O system by two methods: arc melting using $\mathrm{Li}_{2} \mathrm{CO}_{3}$, $\mathrm{TiO}_{2}$ and $\mathrm{Ti}$, and sintering mixtures of $\mathrm{Li}_{2} \mathrm{Ti}_{2} \mathrm{O}_{5}$ and $\mathrm{Ti}_{2} \mathrm{O}_{3}$ at $800-1480^{\circ} \mathrm{C}$ under $\mathrm{He}$ or Ar atmosphere. ${ }^{1)}$ Single crystals of $\mathrm{LiTi}_{2} \mathrm{O}_{4}$ were prepared by the electrolysis of molten salts or a flux method. ${ }^{3)-5)}$ Murphy et al. reported a unique method of obtaining a powder sample of $\mathrm{LiTi}_{2} \mathrm{O}_{4}$ via the soft-chemical route. ${ }^{\text {) }}$ Electrochemical insertion of $\mathrm{Li}^{+}$ions into anatase-type $\mathrm{TiO}_{2}$ in molten salt $\mathrm{LiCl}$ could produce $\mathrm{LiTiO}_{2}$ and $\mathrm{LiTi}_{2} \mathrm{O}_{4}{ }^{7)} \mathrm{A}$ thin film of $\mathrm{LiTi}_{2} \mathrm{O}_{4}$ could be formed by $\mathrm{r}$. f. magnetron sputtering, or pulse laser deposition. ${ }^{8), 9)}$ Feng et al. succeeded in the preparation of a powder sample of $\mathrm{LiTi}_{2} \mathrm{O}_{4}$ by solid-state reaction from $\mathrm{LiOH}$, $\mathrm{TiO}_{2}$ and $\mathrm{Ti}_{2} \mathrm{O}_{3}$ in $\mathrm{Ar}$ atmosphere at $890^{\circ} \mathrm{C} .{ }^{10}$ )

We reported that perovskite-type titanates $\mathrm{ATiO}_{3}(\mathrm{~A}: \mathrm{Ca}, \mathrm{Sr}$, $\mathrm{Ba}$ ) could be prepared from the lepidocrocite-type potassium titanate at a temperature lower than that of the conventional solidstate reaction, ${ }^{11), 12)}$ and this preparation method was useful for loading a catalytic metal atom in the perovskite-type structure. ${ }^{13)}$ In the course of this investigation, $\mathrm{LiTi}_{2} \mathrm{O}_{4}$ could be obtained by the reaction of lepidocrocite-type potassium titanate and molten $\mathrm{LiCl}$ at $750-850^{\circ} \mathrm{C}$ in a stream of $\mathrm{H}_{2}$ gas. In this paper, we will describe the synthesis of spinel-type $\mathrm{LiTi}_{2} \mathrm{O}_{4}$ using molten salt and its properties.

\section{Experimental}

A lepidocrocite-type potassium titanate was used in a commercial chemical (Terases Lss) obtained from Otsuka Chemical Co., Ltd. The mixture of potassium titanate and $\mathrm{LiCl}$ with the molar ratio of 1:4 was put into an alumina boat and heated at 600

\footnotetext{
Corresponding author: N. Kumada; E-mail: kumada@yamanashi. ac.jp
}

$1000^{\circ} \mathrm{C}$ for $3 \mathrm{~h}$ in a stream of $\mathrm{H}_{2}$ gas. The product was washed with distilled water to dissolve the potassium and lithium salts, and separated by filtration, washed with distilled water and dried at $50^{\circ} \mathrm{C}$. The products were identified by X-ray powder diffraction patterns using monochromated $\mathrm{Cu} \mathrm{K} \alpha$ radiation. The lattice constants were determined from the X-ray powder diffraction patterns measured in the $2 \theta$ range from 10 to $120^{\circ}$. The morphology of the particle was observed by scanning electron microscopy (SEM). The chemical composition was analyzed as follows. The prepared $\mathrm{LiTi}_{2} \mathrm{O}_{4}$ was converted to hydrated titanium oxide in concentrated $\mathrm{HNO}_{3}+\mathrm{HCl}$ solution $\left(\mathrm{HNO}_{3} 5 \mathrm{~mL}+\mathrm{HCl}\right.$ $15 \mathrm{~mL}+\mathrm{H}_{2} \mathrm{O} 10 \mathrm{~mL}$ ) under hydrothermal condition at $200^{\circ} \mathrm{C}$ for $12 \mathrm{~h}$. The product was separated by filtration and the amounts of lithium and potassium ions in the solution were determined by an atomic absorption spectroscopy. The solid was heated at $1000^{\circ} \mathrm{C}$ for $1 \mathrm{~h}$ and the product (rutile-type $\mathrm{TiO}_{2}$ ) was weighed. The oxygen content was determined on the basis of mass gain by TG analysis. The temperature dependence of the DC magnetic susceptibility was measured with zero-field cooling modes in the temperature range from 2.5 to $20 \mathrm{~K}$ in an external field of 10 Oe using a superconducting quantum interference device magnetometer (MPMS-5S, Quantum Design).

\section{Results and discussion}

Figure 1 shows the X-ray powder diffraction patterns of products prepared from potassium titanate and molten $\mathrm{LiCl}$ at $650-1000^{\circ} \mathrm{C}$. The spinel-type phase was observed in the products at $650-900^{\circ} \mathrm{C}$. An approximate single phase of spinel-type $\mathrm{LiTi}_{2} \mathrm{O}_{4}$ was obtained at $850^{\circ} \mathrm{C}$, and its X-ray powder diffraction pattern indicated a small amount of $\mathrm{TiO}$ as well as the spinel-type compound. The X-ray powder pattern of the product prepared at $800^{\circ} \mathrm{C}$ showed unidentified weak diffraction peaks at approximately 10 and $20^{\circ}$ in $2 \theta$ degree. Those of the products prepared at $650-750^{\circ} \mathrm{C}$ showed the coexistence of a small amount of rutile-type $\mathrm{TiO}_{2}$. At above $900^{\circ} \mathrm{C}$, ramsdelite-type $\mathrm{Li}_{2} \mathrm{Ti}_{3} \mathrm{O}_{7}$ appeared, and at $1000^{\circ} \mathrm{C}$, it was obtained as a single phase. This phase change from spinel to ramsdelite-types was confirmed with the previous work by Gover et $\mathrm{al},{ }^{14)}$ in which a phase transition from the spinel to ramsdelite occurred between 875 and $925^{\circ} \mathrm{C}$.

Figure 2 shows the temperature dependence of magnetic susceptibility of the products prepared at 800,850 and $900^{\circ} \mathrm{C}$. 


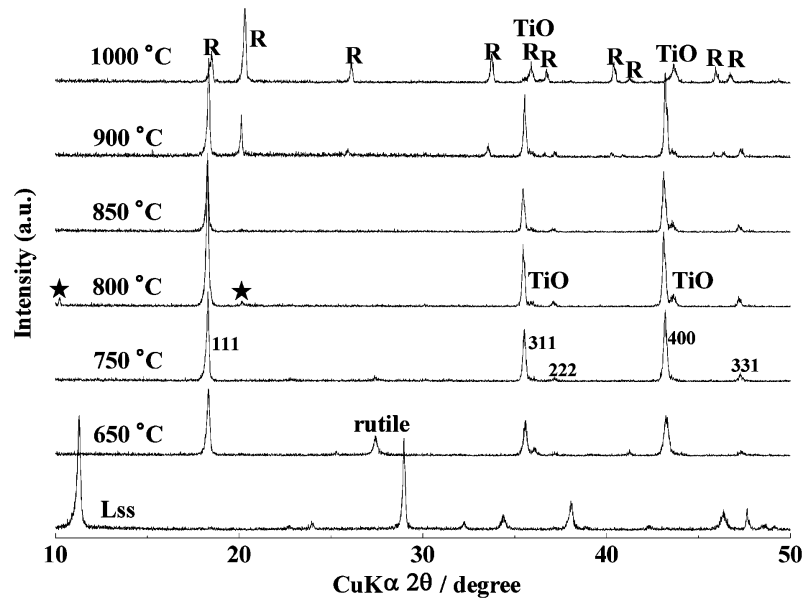

Fig. 1. X-ray powder diffraction patterns of starting compound and products prepared at $650-1000^{\circ} \mathrm{C}$. The star denotes an unidentified peak.

$10.5 \mathrm{~K}$

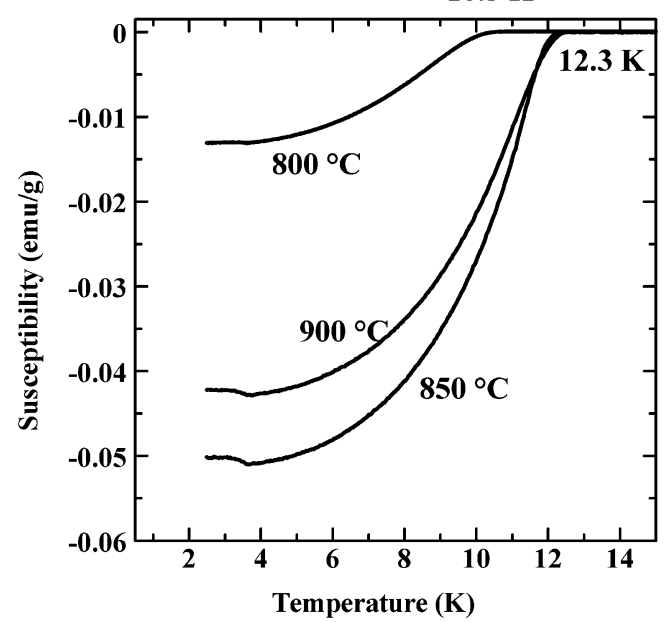

Fig. 2. Temperature dependence of magnetic susceptibility of products prepared at 800,850 and $900^{\circ} \mathrm{C}$.

This broad superconductive transition is a typical example for polycrystalline samples. The product at $750^{\circ} \mathrm{C}$ exhibited no superconductive diamagnetism down to $2.5 \mathrm{~K}$. The superconductive critical temperature $T_{c}$ of the products at 850 and $900^{\circ} \mathrm{C}$ was $12.3 \mathrm{~K}$, and the volume fraction of superconductivity for the product at $850^{\circ} \mathrm{C}$ was calculated to be $23 \%$. According to Harrison et al. ${ }^{15)}$ and Ueda et al., ${ }^{16)}$ the volume fraction of superconductivity for the $\mathrm{Li}_{1+x} \mathrm{Ti}_{2-x} \mathrm{O}_{4}$ powder sample depended on the value of $x$ in $\mathrm{Li}_{1+x} \mathrm{Ti}_{2-x} \mathrm{O}_{4}$, and the volume fraction for $x=$ 0.05 was $50-60 \%$. When compared with these previous data, our sample was inferior to the samples prepared by solid-state reaction. $T_{c}$ of the product at $800^{\circ} \mathrm{C}$ decreased to $10.5 \mathrm{~K}$, and its volume fraction of superconductivity was also decreased to $5.8 \%$. Although a small amount of $\mathrm{TiO}$ was observed in the samples prepared above $800^{\circ} \mathrm{C}$, a stoichiometric $\mathrm{TiO}$ was reported to have $T c=2.3 \mathrm{~K}^{17)}$

The $\mathrm{Li} / \mathrm{Ti}$ ratios of the products at 750,800 and $850^{\circ} \mathrm{C}$ were $0.53,0.53$ and 0.54 , respectively, and no potassium atom was detected in these samples by chemical analysis. In the TG curve of the sample prepared at $850^{\circ} \mathrm{C}$, the mass gain $(2.17$ mass $\%$ ) was observed and from this value, the oxygen content was calculated to be 4.2. Since this oxygen content was overestimated because of

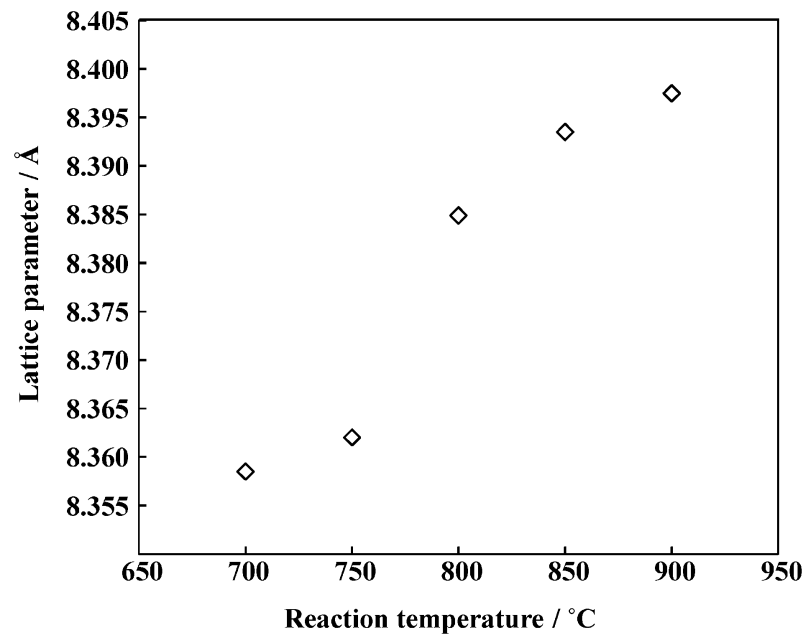

Fig. 3. Lattice parameter vs reaction temperature for spinel-type $\mathrm{LiTi}_{2} \mathrm{O}_{4}$ obtained by molten salt synthesis. The standard deviation of the lattice parameter is within the size of the marker.

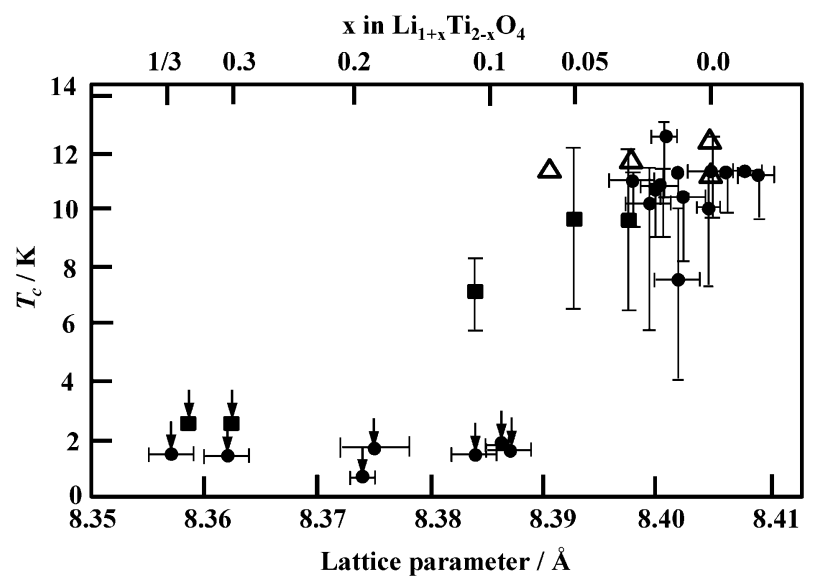

Fig. 4. Superconducting transition temperature vs value of $x$ in $\mathrm{Li}_{1+x} \mathrm{Ti}_{2-x} \mathrm{O}_{4}$ and the lattice parameter. The filled circles, filled square and open triangles denote the powder samples obtained by Johnston, the sample prepared in this work and single crystal samples, ${ }^{3)-5)}$ respectively. The data obtained in this work and from single-crystal samples are plotted against the lattice parameter. The arrows indicate that no superconductivity was observed above the temperature indicated by the tip of the arrow. The vertical error bar for superconducting samples marks the temperature at which 10 and $90 \%$ of the samples become superconducting. The vertical error bar for single-crystal samples is omitted.

a small amount of impurity phase $\mathrm{TiO}$, the exact oxygen content in the spinel-type phase was estimated to be 4.0-4.1. Although the $\mathrm{Li} / \mathrm{Ti}$ ratio was almost constant, regardless of the reaction temperature, the lattice parameters increased with the reaction temperature as shown in Fig. 3. The chemical composition of the product at $850^{\circ} \mathrm{C}$, which is the sample with the lowest amount of impurity phase and the highest $T_{c}$, can be represented as $\mathrm{Li}_{1.05^{-}}$ $\mathrm{Ti}_{1.95} \mathrm{O}_{4}$, and its lattice parameter is $a=8.3935(2) \AA$. According to investigations ${ }^{3)-5)}$ of single crystals of $\mathrm{LiTi}_{2} \mathrm{O}_{4}$, their lattice parameter and critical temperature $T_{c}$ were varied from 8.3914 to $8.4095(12) \AA$ and 11.3 to $12.7 \mathrm{~K}$, respectively, and every transition width was very small $(\sim 1.5 \mathrm{~K})$. Johnston ${ }^{18)}$ reported a diagram of the relationship among the lattice parameter, chemical composition and $T_{c}$, and the data obtained in this work and from single-crystal samples ${ }^{3)-5}$ ) were plotted in Johnston's diagram, 

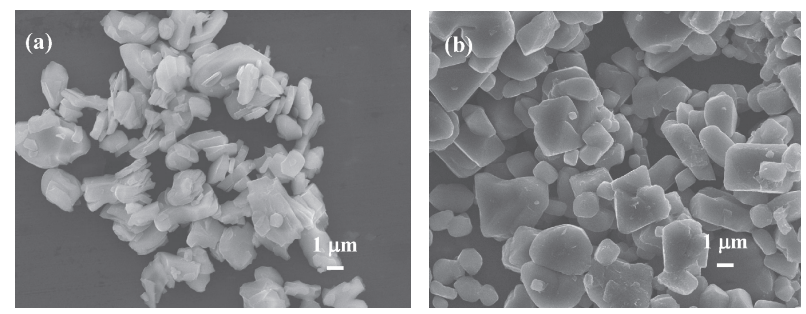

Fig. 5. SEM imagess of (a) starting compound and (b) product prepared at $850^{\circ} \mathrm{C}$.

as shown in Fig. 4. Most of the superconducting samples with $T_{c}>10 \mathrm{~K}$ exist in the region of $a>8.39$ in the lattice parameter, and samples with shorter lattice parameters, which have a higher lithium content, did not exhibit superconductivity or have lower $T_{c}$ $(\sim 1.5 \mathrm{~K}){ }^{2)}$ The relationship between site distributions of $\mathrm{Li}$ and $\mathrm{Ti}$ atoms in the spinel-type structure of $\mathrm{Li}_{1+x} \mathrm{Ti}_{2-x} \mathrm{O}_{4}$ and superconductive property has been discussed, and the large variation of $T_{c}$ was explained by not only nonstoichiometry owing to the preparation method but also lithium deficiency and the associated Ti network disorder. ${ }^{2), 18)-20)}$ Nonetheless the trend for the powder sample of $\mathrm{Li}_{1+x} \mathrm{Ti}_{2-x} \mathrm{O}_{4}$ prepared using molten salt is consistent with the previous data in Johnston's diagram.

This preparation method with molten salt can easily crystallize the spinel-type $\mathrm{LiTi}_{2} \mathrm{O}_{4}$; however, a small amount of the second phase, $\mathrm{TiO}$ coexisted and excess $\mathrm{Li}$ in the molten salt cannot control the chemical composition.

Figure 5 shows SEM images of the starting compound and the product prepared at $850^{\circ} \mathrm{C}$. The starting compound has flake like particles with $2-5 \mu \mathrm{m}$ size and the morphology of the particles prepared at $850^{\circ} \mathrm{C}$ showed an irregular shape with a particle size of $1-10 \mu \mathrm{m}$. This morphological change comes from crystal growth in molten salt.

\section{Conclusion}

The molten salt synthesis with lepidocrocite-type potassium titanate could easily produce the superconductive spinel-type $\mathrm{LiTi}_{2} \mathrm{O}_{4}$ with $T_{c}=12.3 \mathrm{~K}$. The optimum synthetic condition was a reaction temperature of $850^{\circ} \mathrm{C}$ for $3 \mathrm{~h}$ in a stream of $\mathrm{H}_{2}$ gas. The chemical composition and lattice parameter were $\mathrm{Li}_{1.05} \mathrm{Ti}_{1.95} \mathrm{O}_{4}$ and $a=8.3935(2) \AA$, respectively. This method was available for the preparation of spinel-type titanate as well as perovskitetype ones.

\section{References}

1) D. C. Johnston, H. Parkash, W. H. Zachariasen and R. Viswanathan, Mater. Res. Bull., 8, 777-784 (1973).

2) E. G. Moshopoulou, J. Am. Ceram. Soc., 82, 3317-3320 (1999).

3) O. Durrneyer, J. P. Kappler, A. Deroy, M. Drillon and J. J. Capponi, Solid State Commun., 74, 621-624 (1990).

4) J. Akimoto, Y. Goto, K. Kawaguchi and Y. Oosawa, J. Solid State Chem., 96, 446-450 (1992).

5) C. Chen, M. Spears, F. Wondre and J. Ryan, J. Cryst. Growth, 250, 139-145 (2003).

6) R. J. Cava, D. W. Murphy, S. Zahurak, A. Santro and R. S. Roth, J. Solid State Chem., 53, 125-135 (1984).

7) K. Jiang, X. Hu, H. Sun, D. Wang, X. Jin, Y. Ren and G. Z. Chen, Chem. Mater., 16, 4324-4329 (2004).

8) T. Inukai, T. Murakami and T. Inamura, Thin Solid Films, 94, 47-50 (1982).

9) A. Kumatani, T. Ohsawa, R. Shimizu, Y. Takagi, S. Shiraki and T. Hitosugi, Appl. Phys. Lett., 101, 123103 (2012).

10) C. Q. Feng, L. Li, Z. P. Guo, D. Q. Shi, R. Zeng and X. J. Zhu, J. Alloys Compd., 478, 767-770 (2009).

11) N. Kumada, H. Ogiso, S. Wada, Y. Yonesaki, T. Takei, N. Kinomura, T. Iijima and T. Watanabe, J. Ceram. Soc. Japan, 118, 738-740 (2010).

12) N. Kumada, A. Miura, T. Takei, I. B. Adilina and S. Shimazu, J. Ceram. Soc. Japan, 121, 74-79 (2013).

13) I. B. Adilina, T. Hara, N. Ichikuni, N. Kumada and S. Shimazu, Bull. Chem. Jpn., 86, 146-152 (2013).

14) R. K. B. Gover, J. T. S. Irvine and A. A. Finch, J. Solid State Chem., 132, 382-388 (1997).

15) M. R. Harrison, P. P. Edwards and J. B. Goodenough, Philos. Mag. B, 52, 679-699 (1985).

16) Y. Ueda, T. Tanaka, K. Kosuge, M. Ishikawa and H. Yasuoka, J. Solid State Chem., 77, 401-406 (1988).

17) N. J. Doyle, J. K. Hulm, C. K. Jones, R. C. Miller and A. Tylor, Phys. Lett., 26A, 604-605 (1968).

18) D. C. Johnston, J. Low Temp. Phys., 25, 145-175 (1976).

19) E. Moshopoulou, P. Bordet, J. J. Capponi, C. Chaillout, B. Souletie and A. Sulpice, J. Alloys Compd., 195, 81-84 (1993).

20) E. Moshopoulou, P. Bordet, A. Sulpice and J. J. Capponi, Physica C, 235, 747-748 (1994). 